\title{
Quasi-2D halide perovskites for resistive switching devices with ON/OFF ratios above $10^{9}$
}

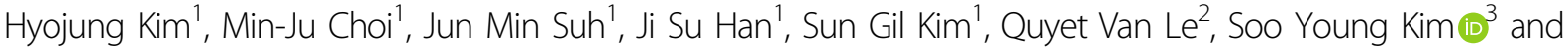 \\ Ho Won Jang (1)
}

\begin{abstract}
Resistive random-access memory (ReRAM) devices based on halide perovskites have recently emerged as a new class of data storage devices, where the switching materials used in these devices have attracted extensive attention in recent years. Thus far, three-dimensional (3D) halide perovskites have been the most investigated materials for resistive switching memory devices. However, 3D-based memory devices display ON/OFF ratios comparable to those of oxide or chalcogenide ReRAM devices. In addition, perovskite materials are susceptible to exposure to air. Herein, we compare the resistive switching characteristics of ReRAM devices based on a quasi-two-dimensional (2D) halide perovskite, $(\mathrm{PEA})_{2} \mathrm{CS}_{3} \mathrm{~Pb}_{4} \mathrm{l}_{13}$, to those based on $3 \mathrm{D} \mathrm{CsPb}{ }_{3}$. Astonishingly, the ON/OFF ratio of the $(\mathrm{PEA})_{2} \mathrm{Cs}_{3} \mathrm{~Pb}_{4} \mathrm{l}_{13}$-based memory devices $\left(10^{9}\right)$ is three orders of magnitude higher than that of the $\mathrm{CsPbl}_{3}$ device, which is attributed to a decrease in the high-resistance state (HRS) current of the former. This device also retained a high ON/OFF current ratio for 2 weeks under ambient conditions, whereas the $\mathrm{CsPb}_{3}$ device degraded rapidly and showed unreliable memory properties after 5 days. These results strongly suggest that quasi-2D halide perovskites have potential in resistive switching memory based on their desirable ON/OFF ratio and long-term stability.
\end{abstract}

\section{Introduction}

Photovoltaic devices are recognized as prospective energy sources ${ }^{1-8}$. As light absorbers, halide perovskites have had a significant impact on solar cell research owing to their remarkable photovoltaic properties, such as their long charge diffusion length and low exciton binding energies $^{9-16}$. In particular, the current-voltage $(I-V)$ hysteresis of halide perovskites has broadened their applications to electronic devices beyond photovoltaics, such as field-effect transistors, resistive-switching memory, and artificial synapses ${ }^{17-19}$. The defects that cause sweep-dependent hysteresis migrate in the halide perovskite layer, causing a switch in the current direction upon the application of a weak electric field ${ }^{20}$.

Correspondence: Quyet Van Le (levanquyet@dtu.edu.vn) or Soo Young Kim (sooyoungkim@korea.ac.kr) or Ho Won Jang (hwjang@snu.ac.kr)

'Department of Materials Science and Engineering, Seoul National University, Seoul 08826, Republic of Korea

${ }^{2}$ Institute of Research and Development, Duy Tan University, Da Nang 550000, Vietnam

Full list of author information is available at the end of the article.
In general, halide perovskites, which are threedimensionally (3D) structured compounds with the chemical formula $\mathrm{ABX}_{3}$, consist of monovalent cations in the A-site, divalent cations in the B-site, and halide anions in the $\mathrm{X}$-site ${ }^{21}$. 3D halide perovskites, such as $\mathrm{MAPbI}_{3}(\mathrm{MA}=$ $\mathrm{CH}_{3} \mathrm{NH}_{3}$ ) or $\mathrm{CsPbI}_{3}$, have been mostly studied for ReRAM devices; these devices have ON/OFF ratios on the order of $10^{6}$ with multilevel resistive switching and low operating voltages ${ }^{22,23}$.

ReRAM devices based on halide perovskites have recently received attention as a potential research topic; however, some issues need to be resolved. Compared with conventional ReRAM devices based on metal oxides ${ }^{24-26}$, 3D halide perovskite memory devices display low stability in humid and ambient atmospheres, leading to the degradation of the switching characteristics of the memory devices. More importantly, the ON/OFF ratio should be higher than $10^{10}$ to be commercialized, because the resistances of the bit and selector lines are considered in terms of the high-density layer of the memory array.

\section{(c) The Author(s) 2020}

(c) (i) Open Access This article is licensed under a Creative Commons Attribution 4.0 International License, which permits use, sharing, adaptation, distribution and reproduction cc) in any medium or format, as long as you give appropriate credit to the original author(s) and the source, provide a link to the Creative Commons license, and indicate if changes were made. The images or other third party material in this article are included in the article's Creative Commons license, unless indicated otherwise in a credit line to the material. If material is not included in the article's Creative Commons license and your intended use is not permitted by statutory regulation or exceeds the permitted use, you will need to obtain permission directly from the copyright holder. To view a copy of this license, visit http://creativecommons.org/licenses/by/4.0/. 


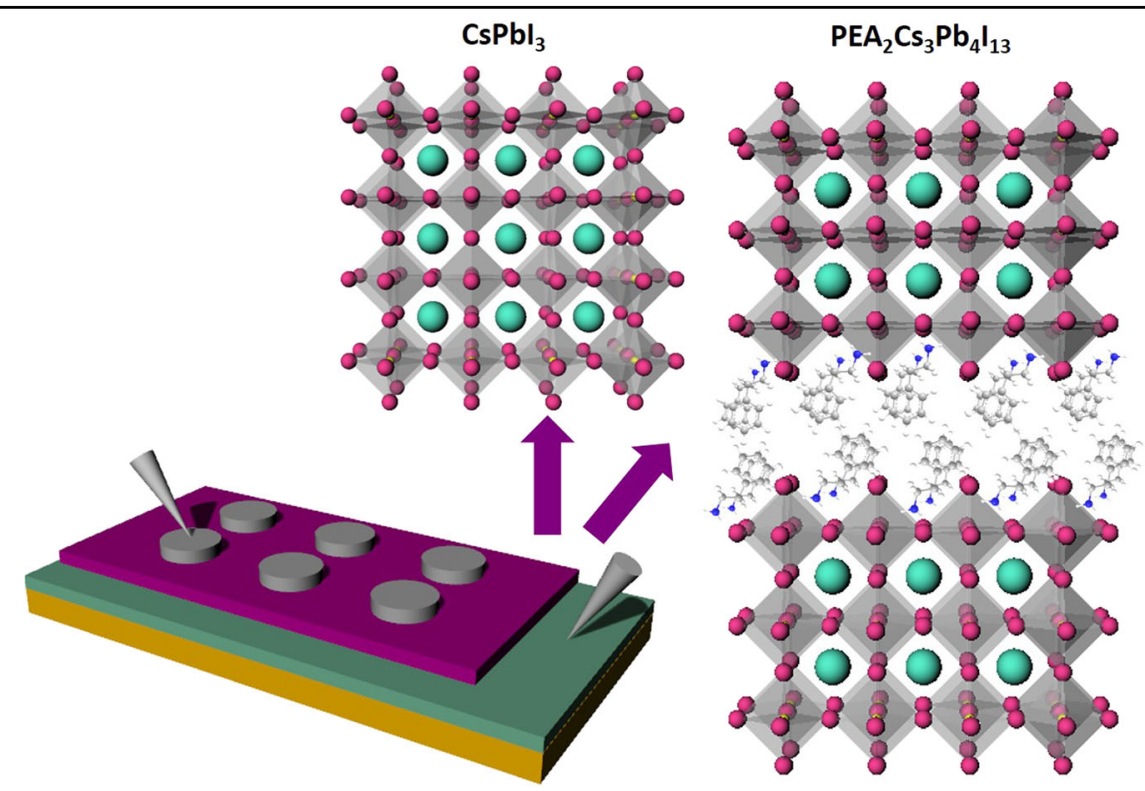

Fig. 1 Schematic illustration of the resistive memory device structure and resistive switching materials $\mathrm{CsPb}_{3}$ and $\left(\mathrm{PEA}_{2} \mathrm{Cs}_{3} \mathrm{~Pb}_{4} \mathrm{l}_{13}\right.$

To address these issues, quasi-two-dimensional (2D) halide perovskites have been considered as a means of improving the ON/OFF ratio and preventing device degradation in air ${ }^{27,28}$. Quasi-2D halide perovskites have the general formula $\left(\mathrm{RNH}_{3}\right)_{2} \mathrm{~A}_{n-1} \mathrm{~B}_{\mathrm{n}} \mathrm{X}_{3 n+1}(n=1,2,3, \ldots)$, where $\mathrm{RNH}_{3}$ is a large organic cation such as a large aliphatic or aromatic alkylammonium cation ${ }^{29-32}$. Thus, as the $n$-values decrease, the dimensionality of halide perovskites changes from $3 \mathrm{D}$ to quasi-2D and 2D structures. Quasi-2D halide perovskites, which are formed by introducing large organic cations into 3D perovskites, have wider bandgaps ${ }^{33-35}$, which make the Schottky barrier at the interface top electrode much higher. This behavior in turn lowers the high-resistance state (HRS) current, which results in an increase in the ON/OFF ratio. Furthermore, the large organic cation between the quasi2D perovskite layers prevents the device from breaking down because of the hydrophobicity of the alkyl amines $^{36-39}$. Recently, ReRAM devices were reported with ON/OFF ratios ranging from $10^{5}$ to $10^{7}$, which are still too low to show commercial promise $e^{40,41}$.

In this study, $(\mathrm{PEA})_{2} \mathrm{Cs}_{3} \mathrm{~Pb}_{4} \mathrm{I}_{13} \quad(\mathrm{PEA}=$ phenethylammonium) and $\mathrm{CsPbI}_{3}$ are employed as the resistive switching elements in a ReRAM device to compare the dependence of the switching behavior on the 3D and quasi-2D halide perovskites. We successfully fabricate a $(\mathrm{PEA})_{2} \mathrm{Cs}_{3} \mathrm{~Pb}_{4} \mathrm{I}_{13}$ ReRAM device with the Ag/ (PEA) ${ }_{2} \mathrm{Cs}_{3} \mathrm{~Pb}_{4} \mathrm{I}_{13} / \mathrm{Pt}$ (platinum) $/ \mathrm{Ti} / \mathrm{SiO}_{2} / \mathrm{Si}$ structure, where the perovskite resistive switching layer is synthesized on a Pt-coated silicon substrate by solution processing at low temperature. The devices exhibit bipolar resistive switching behavior and ultralow operating voltages. Furthermore, the ON/OFF ratios $\left(>10^{9}\right)$ of the $(\mathrm{PEA})_{2} \mathrm{Cs}_{3} \mathrm{~Pb}_{4} \mathrm{I}_{13}$ ReRAM devices are noticeably higher than those of the $\mathrm{CsPbI}_{3}$ device, with long-term stability under ambient conditions. This study provides an opportunity to investigate the effect of the dimensionality of halide perovskites on the resistive switching of devices for use in next-generation high-performance nonvolatile memory.

\section{Results and discussion}

Figure 1 presents a schematic illustration of the device structure and the resistive switching materials $\mathrm{CsPb}_{3}$ and (PEA) ${ }_{2} \mathrm{Cs}_{3} \mathrm{~Pb}_{4} \mathrm{I}_{13}$. Vertical stacks of the Ag top electrode/ $\mathrm{CsPbI}_{3}$ or $(\mathrm{PEA})_{2} \mathrm{Cs}_{3} \mathrm{~Pb}_{4} \mathrm{I}_{13} / \mathrm{Pt}$ bottom electrode $/ \mathrm{Ti} / \mathrm{SiO}_{2} /$ $\mathrm{Si}$ structures were fabricated. For the low-temperature allsolution process, $\mathrm{CsPbI}_{3}$ and $(\mathrm{PEA})_{2} \mathrm{Cs}_{3} \mathrm{~Pb}_{4} \mathrm{I}_{13}$ films were successfully synthesized by the spin-coating method and by the thermal evaporation method using a dot-patterned shadow mask. Ag top electrodes were formed on the switching layers.

Compared with $\mathrm{CsPbI}_{3}$, in a 3D halide perovskite, the two organic PEA cation layers that are stacked between the inorganic layers can increase the bandgap. Although the organic PEA cations do not influence the electronic states around the band edge, the steric hindrance and other structural effects caused by the organic PEA cations bring about structural changes in the halide perovskite frameworks, which indirectly influences the increase in the bandgap. Notably, the bandgap increase has a significant influence on the switching performance ${ }^{42}$.

Figure 2a, b present scanning electron microscopy (SEM) images of the $\mathrm{CsPbI}_{3}$ and $(\mathrm{PEA})_{2} \mathrm{Cs}_{3} \mathrm{~Pb}_{4} \mathrm{I}_{13}$ 
(a)

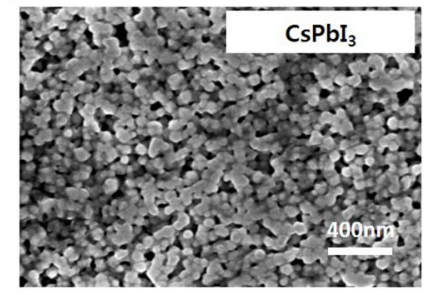

(c)
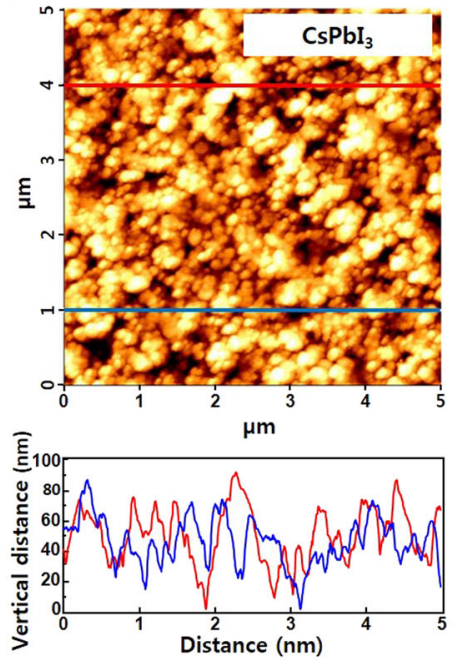

(b)

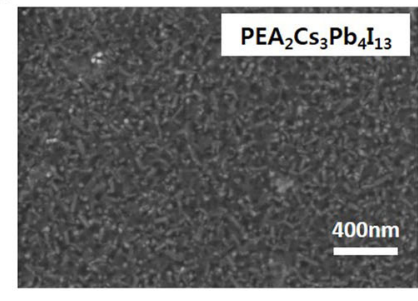

(d)
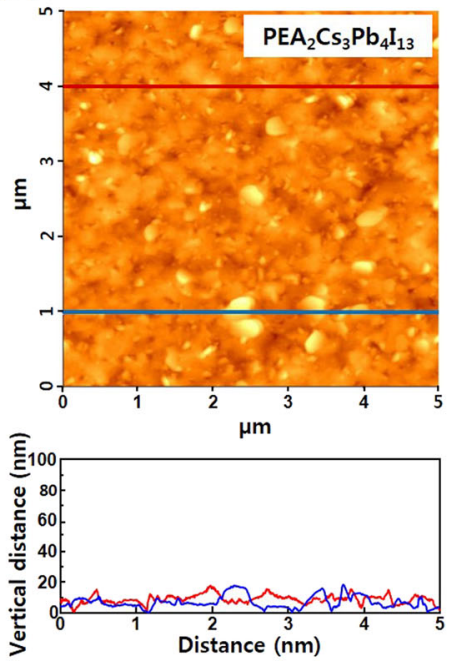

(e)
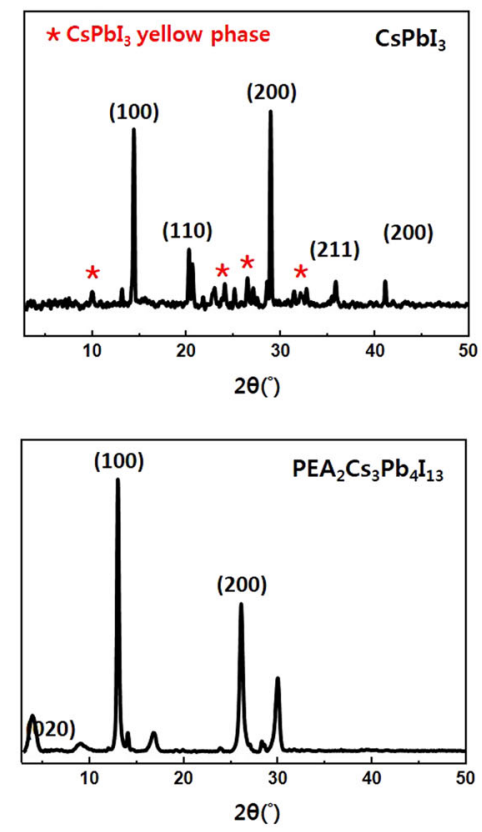

Fig. 2 Properties of the halide perovskite films. a, b Top-view SEM images of the $\mathrm{CsPb}_{3}(\mathbf{a})$ and $(\mathrm{PEA})_{2} \mathrm{Cs}_{3} \mathrm{~Pb}_{4} \mathrm{l}_{13}$ (b) perovskite films. $\mathbf{c}$, $\mathbf{d}$ AFM images of the $\mathrm{CsPb}_{3}(\mathbf{c})(\mathrm{RMS}=15.0 \mathrm{~nm})$ and the $(\mathrm{PEA})_{2} \mathrm{Cs}_{3} \mathrm{~Pb}_{4} \mathrm{I}_{13}(\mathbf{d})$ perovskite film (RMS $\left.=15.0 \mathrm{~nm}\right)$. The tips move $5 \mu \mathrm{m}$ through the red and blue lines to measure the roughness. e X-ray diffraction patterns of $\mathrm{CsPbl}_{3}$ and $(\mathrm{PEA})_{2} \mathrm{Cs}_{3} \mathrm{~Pb}_{4} \mathrm{l}_{13}$ thin films on a glass substrate

perovskite layers synthesized on Pt-coated silicon substrates. For both samples, the thickness was $\sim 300$ $-350 \mathrm{~nm}$ (Supplementary Fig. S1, Supporting Information), with good film quality and high film coverage. To achieve a smooth surface, the Pt-coated silicon substrates were subjected to ultraviolet ozone cleaning before coating with the perovskite films.

As shown in Fig. 2c, d, the surface of both perovskite layers was evaluated by atomic force microscopy (AFM) with a scan size of $5 \mu \mathrm{m} \times 5 \mu \mathrm{m}$. Ultralow roughness was obtained for the $(\mathrm{PEA})_{2} \mathrm{Cs}_{3} \mathrm{~Pb}_{4} \mathrm{I}_{13}$ film, with a root mean square roughness of $3.0 \mathrm{~nm}$, which is much lower than that of the $\mathrm{CsPbI}_{3}$ film $(15.0 \mathrm{~nm})$. It is suspected that the addition of PEAI (Phenethylammonium iodide) to the precursor solution impedes the growth of the perovskite crystal due to the strong hydrogen bond between the hydrogen atom of PEAI and the halide atom in PbI. Thus, the PEAI addition to form (PEA) ${ }_{2} \mathrm{Cs}_{3} \mathrm{~Pb}_{4} \mathrm{I}_{13}$, a quasi-2D halide perovskite, dramatically improved the film uniformity ${ }^{43,44}$.

$\mathrm{X}$-ray diffraction (XRD) measurements were conducted to verify the accurate phase of the $3 \mathrm{D}$ perovskite $\left(\mathrm{CsPbI}_{3}\right.$ black phase) and quasi-2D perovskite ((PEA) $\left.{ }_{2} \mathrm{Cs}_{3} \mathrm{~Pb}_{4} \mathrm{I}_{13}\right)$. As shown in Fig. 2e, the XRD pattern of the $\mathrm{CsPbI}_{3}$ sample shows sharp peaks at (100) and (200), indicating that the obtained perovskite film is highly oriented. A shoulder appeared next to the (110) peak, providing evidence of strain in the crystal, which allows the crystallization of $\mathrm{CsPbI}_{3}$ in the cubic phase ${ }^{45}$. Nevertheless, peaks of the yellow phase were also observed due to the metastable nature of cubic $\mathrm{CsPbI}_{3}$. Upon incorporating PEAI into $\mathrm{CsPbI}_{3}$ to obtain the quasi-2D perovskite, a low-angle diffraction peak appeared, which can be attributed to the typical reflections from the layered structure $^{46}$. No XRD peaks related to yellow-phase $\mathrm{CsPbI}_{3}$ were observed for the quasi-2D perovskite sample. This result indicates that the addition of PEAI to $\mathrm{CsPbI}_{3}$ not only improves the morphology but also considerably boosts the stability of the perovskite film by inhibiting the transformation from the black to yellow phase of $\mathrm{CsPbI}_{3}$.

To compare the switching characteristics of the $\mathrm{CsPbI}_{3}-$ and (PEA) ${ }_{2} \mathrm{Cs}_{3} \mathrm{~Pb}_{4} \mathrm{I}_{13}$-based memory devices, the $I-V$ characteristics of both devices were measured under a direct current-voltage sweep. Figure 3 displays the typical current-voltage curves of the $\mathrm{Ag} / \mathrm{CsPbI}_{3} / \mathrm{Pt}$ (a) and $\mathrm{Ag} /$ (PEA) ${ }_{2} \mathrm{Cs}_{3} \mathrm{~Pb}_{4} \mathrm{I}_{13} / \mathrm{Pt}$ (b) devices, where the voltage was applied to the top Ag electrode and the Pt bottom 
(a)

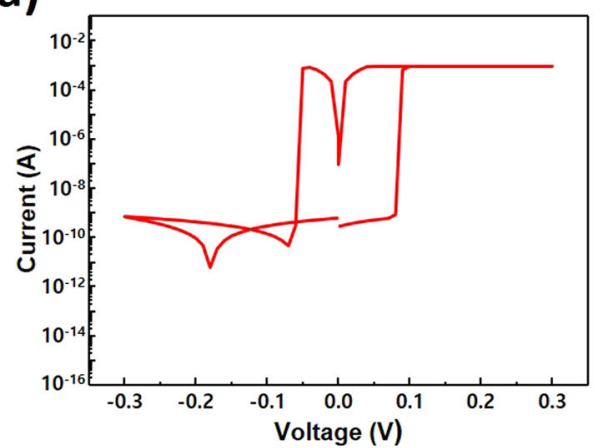

(c)

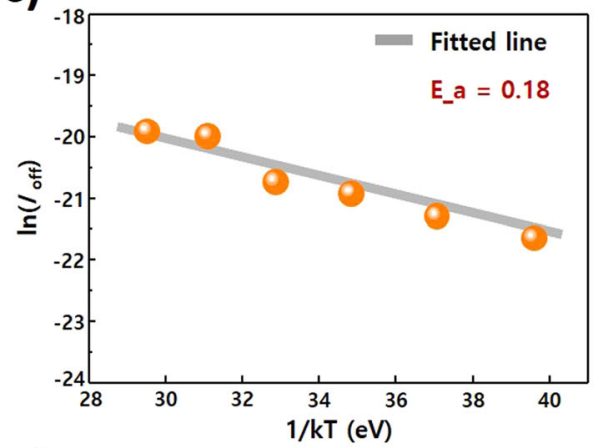

(e)

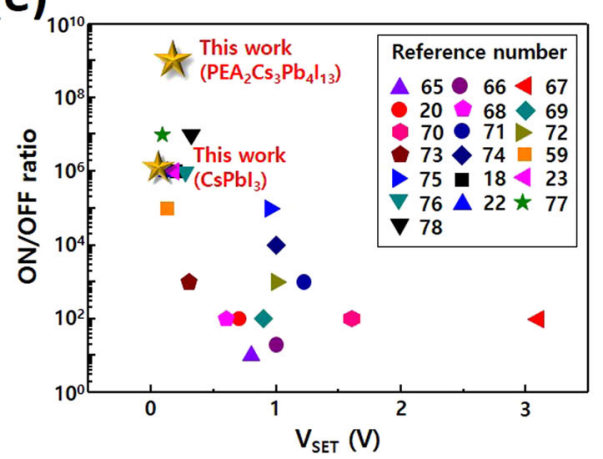

(b)

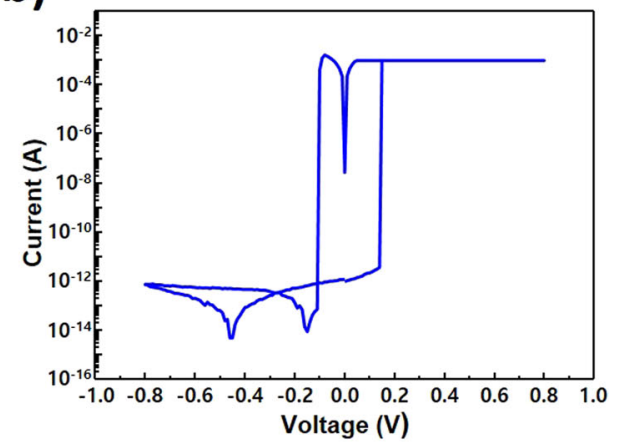

(d)

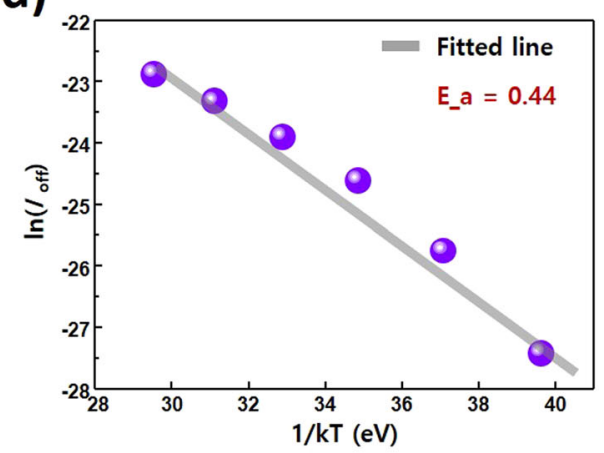

Fig. 3 Typical current-voltage curves, temperature-dependent OFF currents, and comparison of the ON/OFF ratio with various halide perovskite-based ReRAM devices. Typical current-voltage curves of $\mathrm{Ag} / \mathrm{CsPbl} / \mathrm{Pt}(\mathbf{a})$ and $\mathrm{Ag} /(\mathrm{PEA})_{2} \mathrm{Cs}_{3} \mathrm{~Pb}_{4} \mathrm{l}_{13} / \mathrm{Pt}$ (b) devices. Temperaturedependent OFF currents of the $\mathrm{Ag} / \mathrm{CsPb} \mathrm{Cl}_{3} / \mathrm{Pt}$ (c) and $\mathrm{Ag} /(\mathrm{PEA})_{2} \mathrm{Cs}_{3} \mathrm{~Pb}_{4} \mathrm{I}_{13} / \mathrm{Pt}$ (d) devices; the Arrhenius equation was used to deduce $E_{a \text {. }}$ (e). Comparison of the ON/OFF ratio with various halide perovskite-based ReRAM devices, including $\mathrm{CsPb}_{3-}$ and ((PEA) $\mathrm{Cs}_{3} \mathrm{~Pb}_{4} \mathrm{I}_{13}$-based cells

electrode was grounded. Both devices displayed bipolar resistive switching, which indicates that ON/OFF switching occurred at opposite polarities.

Given that the ON/OFF resistive switching operation is explained by the SET and RESET processes for these halide perovskite memory devices, the SET process, which refers to the switching from a HRS (OFF state) to a lowresistance state (LRS; ON state) at a certain positive voltage, showed an abrupt increase. In these memory devices, the abrupt increase in the current during the SET process and the sustained LRS support the formation of conducting filaments with a compliance current (CC) of $10^{-3}$ A. Then, the LRS changed to an HRS when a negative voltage was applied to these devices, which indicates the rupture of the conducting filaments with a $\mathrm{CC}$ of $10^{-2} \mathrm{~A}$. Notably, the ON/OFF ratio for the (PEA) ${ }_{2} \mathrm{Cs}_{3} \mathrm{~Pb}_{4} \mathrm{I}_{13}$-based devices was as high as $\sim 10^{9}$, whereas that of the $\mathrm{CsPbI}_{3}-$ based devices was much lower (by $\sim 10^{6}$ ). The high ON/ OFF ratio of the (PEA) ${ }_{2} \mathrm{Cs}_{3} \mathrm{~Pb}_{4} \mathrm{I}_{13}$-based devices can be explained by the Schottky barrier height.

By changing the dimensionality from 3D for $\mathrm{CsPbI}_{3}$ to quasi-2D for $(\mathrm{PEA})_{2} \mathrm{Cs}_{3} \mathrm{~Pb}_{4} \mathrm{I}_{13}$, the bandgap is widened $^{33-35}$. As the bandgap increases, the Schottky barrier height, which corresponds to the electron flow from the top electrode to the bottom electrode, increases at the interface between the halide perovskite switching 


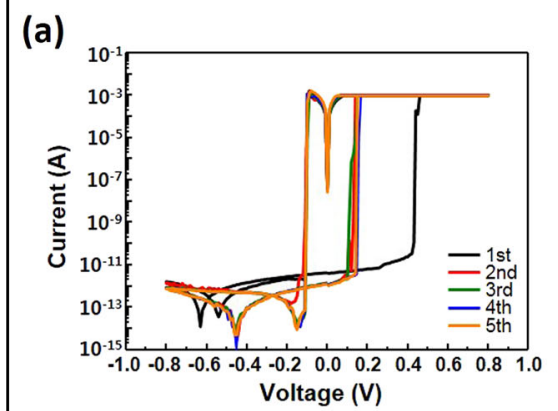

(d)

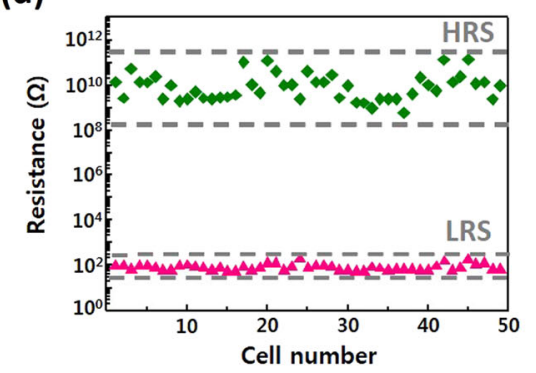

(b)

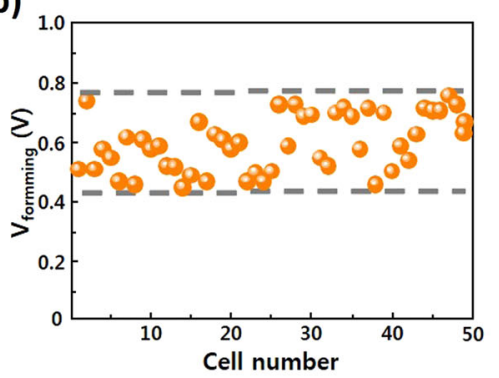

(e)

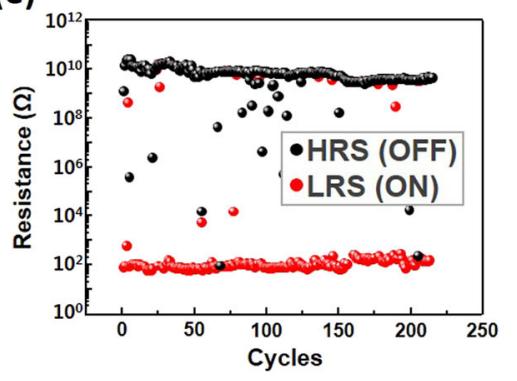

(c)

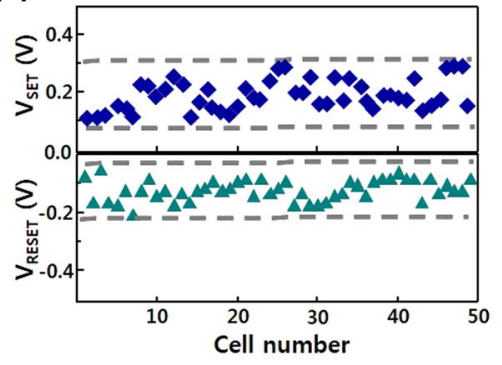

(f)

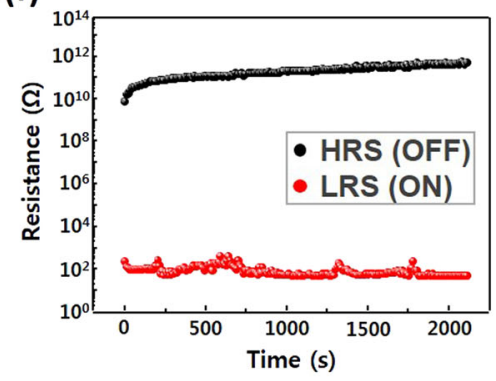

Fig. 4 Resistive-switching performance of the $(\mathrm{PEA})_{2} \mathrm{Cs}_{3} \mathrm{~Pb}_{4} \mathrm{I}_{13}$-based memory device. a Series $I-V$ characteristics of the $A g /(\mathrm{PEA})_{2} \mathrm{Cs}_{3} \mathrm{~Pb} \mathrm{~b}_{4} \mathrm{I}_{13} / \mathrm{Pt}$ cells. b, c Statistically analyzed forming (b), SET, and RESET (c) voltage distributions of 50 different $\mathrm{Ag} /(\mathrm{PEA})_{2} \mathrm{Cs}_{3} \mathrm{~Pb} \mathrm{~b}_{4} \mathrm{I}_{13} / \mathrm{Pt}$ cells. $\mathbf{d}$ High- and lowresistance states of 50 different $\mathrm{Ag} /(\mathrm{PEA})_{2} \mathrm{Cs}_{3} \mathrm{~Pb}_{4} \mathrm{l}_{13} / \mathrm{Pt}$ cells. e Endurance characteristics for the $\left.(\mathrm{PEA})_{2} \mathrm{Cs}_{3} \mathrm{~Pb}_{4}\right|_{13}$ memory device. $\mathbf{f}$ Retention property of the ON and OFF states

layer and Ag top electrode. This means that the increased barrier height caused a reduction of the injected carrier density from the electrode to the perovskite switching layer. As a result, the HRS current decreased, leading to a high ON/OFF ratio.

The electrical thermal activation energy $\left(E_{\mathrm{a}}\right)$ may be another factor influencing the HRS current reduction. Figure $3 \mathrm{c}, \mathrm{d}$ present plots of the HRS current vs. the inverse temperature at $0.02 \mathrm{~V}$. The $E_{\mathrm{a}}$ for carrier migration in the switching layer in the HRS was deduced from the Arrhenius equation. From the linear fitting slope of each curve, the activation energy was estimated using the Arrhenius equation (presented as Eq. (1)):

$$
\ln I_{\text {off }}(T)=\ln I_{0}-\frac{E_{a}}{k T},
$$

where $I_{\text {off }}$ is the current in the HRS, $I_{0}$ is a constant, $E_{\mathrm{a}}$ is the activation energy, $k$ is the Boltzmann constant, and $T$ is the absolute temperature ${ }^{47}$. The distribution of the $E_{\mathrm{a}}$ for the $\mathrm{CsPb}_{3}$ and $(\mathrm{PEA})_{2} \mathrm{Cs}_{3} \mathrm{~Pb}_{4} \mathrm{I}_{13}$ memory devices extracted from this Arrhenius plot was 0.18 and $0.44 \mathrm{eV}$, respectively.

When the conducting filament is broken in the HRS, a small current flows through the trap states by hopping thermally excited electrons ${ }^{48,49}$. The trap state, which is a donor level in the conduction band, is associated with the $E_{\mathrm{a}}$. Compared with the 3D halide perovskite $\left(\mathrm{CsPbI}_{3}\right)$, the quasi-2D halide perovskite $\left((\mathrm{PEA})_{2} \mathrm{Cs}_{3} \mathrm{~Pb}_{4} \mathrm{I}_{13}\right)$ has a larger bandgap and a higher conduction band minimum, leading to deeper trap states. The deep trap states cause the $E_{\mathrm{a}}$ to increase. Thus, the HRS current is decreased.

Therefore, the fact that the Schottky barrier height and the activation energy of quasi-2D (PEA) ${ }_{2} \mathrm{Cs}_{3} \mathrm{~Pb}_{4} \mathrm{I}_{13}$ are higher than those of $3 \mathrm{D}$ perovskites may account for the high ON/OFF ratio of the (PEA) ${ }_{2} \mathrm{Cs}_{3} \mathrm{~Pb}_{4} \mathrm{I}_{13}$-based memory device, originating from the low HRS current.

To compare the superior resistive switching properties of the (PEA) ${ }_{2} \mathrm{Cs}_{3} \mathrm{~Pb}_{4} \mathrm{I}_{13}$-based memory device with representative research studies on halide perovskite-based ReRAMs, the values of the ON/OFF ratios with SET voltages are exhibited, as shown in Supplementary Table S1. In addition, the ON/OFF ratios vs. the SET voltages are plotted in Fig. 3e.

Figure 4 shows the detailed resistive switching performance of the (PEA) ${ }_{2} \mathrm{Cs}_{3} \mathrm{~Pb}_{4} \mathrm{I}_{13}$-based memory device. As shown in Fig. 4a, a series of five sweeps was performed in DC sweep mode at $0 \mathrm{~V} \rightarrow+0.8 \mathrm{~V} \rightarrow 0 \mathrm{~V} \rightarrow-0.8 \mathrm{~V} \rightarrow 0 \mathrm{~V}$ with a semiconductor parameter analyzer to confirm the hysteresis in the $I-V$ profile of the device. In the initial DC sweep, an electroforming process referred to as a kind of "soft breakdown" was needed to achieve stable resistive switching properties ${ }^{50}$, which is analogous to that of general resistive switching memory devices based on electrochemical metallization (ECM). In ECM, the active top electrode is dissolved by oxidation, after which the 
metal cations form a conducting filament passing through the switching layer ${ }^{51}$.

In the $(\mathrm{PEA})_{2} \mathrm{Cs}_{3} \mathrm{~Pb}_{4} \mathrm{I}_{13}$-based memory device, electroforming occurred abruptly at a voltage of $+0.40 \mathrm{~V}$; the operating voltage required for the SET process was $+0.18 \mathrm{~V}$, and that for the RESET process was $-0.10 \mathrm{~V}$. The SET process could proceed at a lower voltage than that of the electroforming process because of the already-formed filament, which makes it easier to pass the SET filament. Initially, the sustained low-current state of the device $\left(10^{-12} \mathrm{~A}\right)$ abruptly changed to the high-current state of the device $\left(10^{-3} \mathrm{~A}\right)$ when the applied voltage exceeded the SET voltage. Subsequently, the sustained high-current state abruptly changed to the low-current state when the applied bias at negative polarity exceeded the RESET voltage. From the series of five $I-V$ sweeps, the reliable and reproducible resistive switching of the (PEA) ${ }_{2} \mathrm{Cs}_{3} \mathrm{~Pb}_{4} \mathrm{I}_{13}$-based ReRAM devices was confirmed.

Figure 4b, c show the statistically analyzed forming, SET, and RESET voltage distributions of 50 different $\mathrm{Ag} /$ $(\mathrm{PEA})_{2} \mathrm{Cs}_{3} \mathrm{~Pb}_{4} \mathrm{I}_{13} / \mathrm{Pt}$ cells for evaluating the uniformity of the operational function of the (PEA) ${ }_{2} \mathrm{Cs}_{3} \mathrm{~Pb}_{4} \mathrm{I}_{13}$ memory devices. From these distributions, there was no significant deviation in the forming voltages of the different 50 cells, nor did the SET and RESET voltages show any meaningful deviation.

Figure $4 \mathrm{~d}$ shows the HRS and LRS values of 50 different $\mathrm{Ag} /(\mathrm{PEA})_{2} \mathrm{Cs}_{3} \mathrm{~Pb}_{4} \mathrm{I}_{13} / \mathrm{Pt}$ cells under applied write/erase voltage pulses. The result confirms that the average ON/OFF ratio did not differ significantly for the devices, which means that the reproducibility of the cells in resistive switching memory devices is superior.

The switching endurance, which confirms the stability and the number of switching cycles, is also one of the key factors influencing the reliability of resistive switching memory devices. Figure $4 \mathrm{e}$ shows the endurance characteristics of the (PEA) ${ }_{2} \mathrm{Cs}_{3} \mathrm{~Pb}_{4} \mathrm{I}_{13}$ memory device, measured by applying alternating current $(\mathrm{AC})$ voltage pulses. Continuous write/erase voltage pulses of $+0.8 \mathrm{~V}$ for the SET process and $-0.8 \mathrm{~V}$ for the RESET process were applied to the memory devices, with a $640 \mu$ s pulse duration and a read voltage of $+0.05 \mathrm{~V}$. The $\mathrm{Ag} /$ $(\mathrm{PEA})_{2} \mathrm{Cs}_{3} \mathrm{~Pb}_{4} \mathrm{I}_{13} / \mathrm{Pt}$ device was functional for 230 endurance cycles, with ON/OFF ratios above $10^{8}$.

The typical data retention for the $\mathrm{ON}$ and OFF states was also evaluated for the $\mathrm{Ag} /(\mathrm{PEA})_{2} \mathrm{Cs}_{3} \mathrm{~Pb}_{4} \mathrm{I}_{13} / \mathrm{Pt}$ cell to test the electrical reliability of the memory device, as shown in Fig. 4f. A constant ON/OFF ratio of $\sim 10^{9}$ was maintained for over $2 \times 10^{3} \mathrm{~s}$ at a reading voltage of $+0.02 \mathrm{~V}$. In the HRS region, a very small current fluctuation was observed, but the HRS and LRS remained constant overall.

To elucidate the current transport mechanisms of the resistive switching behavior, the typical $I-V$ curves of the devices were plotted using a double-logarithmic scale for
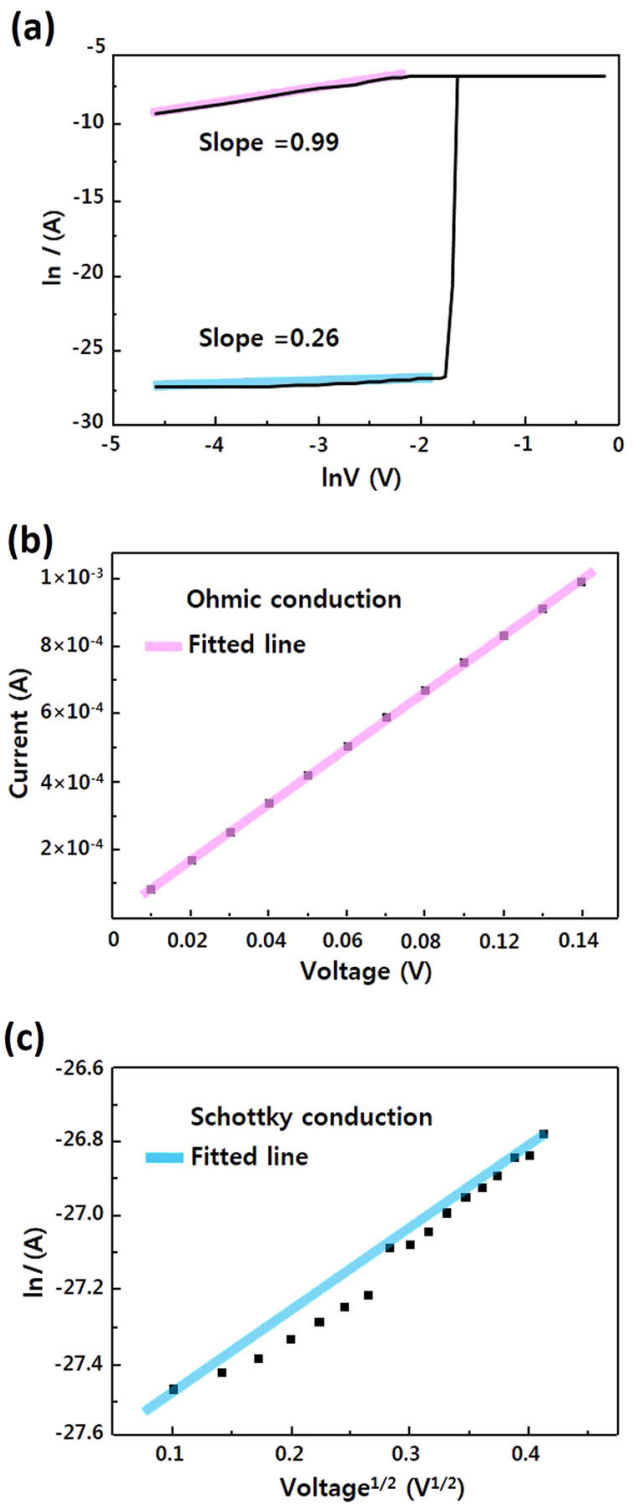

Fig. 5 Current transport mechanisms underlying the resistive switching behavior. a Double-logarithmic scale of the $I-V$ curve of the $\mathrm{Ag} /(\mathrm{PEA})_{2} \mathrm{Cs}_{3} \mathrm{~Pb}_{4} \mathrm{I}_{13} / \mathrm{Pt}$ device. $\mathbf{b}$ Proportional relation of the current density to voltage $(/ \propto V)$ for the LRS. c Relation of the current to the square root of voltage $\left(\ln / \propto V^{1 / 2}\right)$ for HRS

each resistance state, as shown in Fig. 5a. The electrical conduction of the $\mathrm{Ag} /(\mathrm{PEA})_{2} \mathrm{Cs}_{3} \mathrm{~Pb}_{4} \mathrm{I}_{13} / \mathrm{Pt}$ memory device differed in the HRS and LRS during the SET operation under a voltage sweep of $0 \mathrm{~V} \rightarrow+0.8 \mathrm{~V} \rightarrow 0 \mathrm{~V}$. First, it was found that the ohmic conduction plot had a slope of 0.99 , with a linear relation of $\ln I$ vs. $\ln V$ in the LRS region after the abrupt current increase ${ }^{23,52-54}$. In the HRS region, the relation of $\ln I$ vs. $\ln V$ was nonlinear with a slope of 0.26 , which verifies that Schottky emission is dominant $^{23,53,55}$. 
(a)

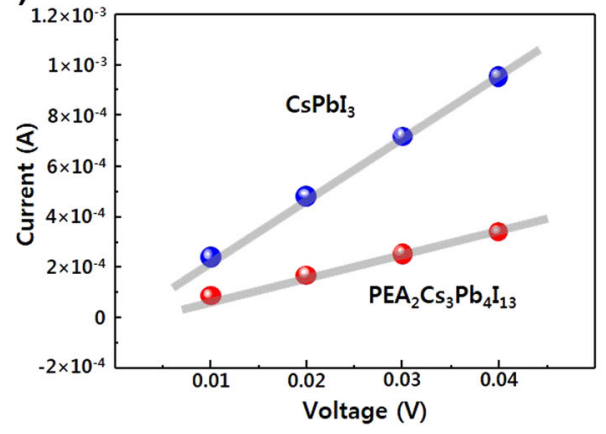

(b)

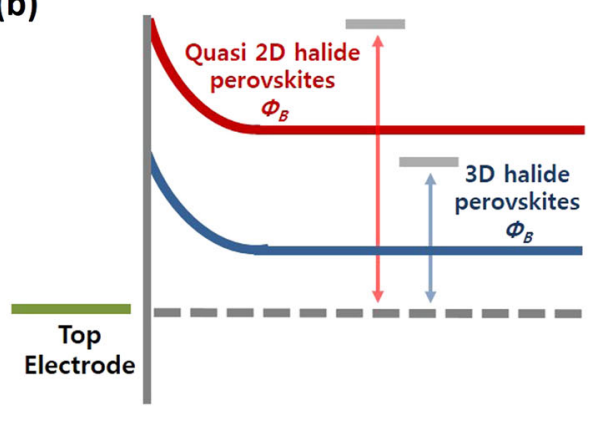

Fig. 6 Comparison of linear replotted I-V curves for the HRS and schematic diagram of the Schottky barrier heights for $\mathrm{CsPbl}_{3}$ and (PEA) ${ }_{2} \mathrm{Cs}_{3} \mathrm{~Pb}_{4} \mathrm{I}_{13}$. a Comparison of linear replotted $I-V$ curves for the HRS of $C s P b l_{3}$ and $(\mathrm{PEA})_{2} \mathrm{Cs}_{3} \mathrm{~Pb}_{4} \mathrm{l}_{13}$ devices. $\mathbf{b}$ Schematic diagram of the Schottky barrier heights for $\mathrm{CsPb}_{3}$ and $(\mathrm{PEA})_{2} \mathrm{Cs}_{3} \mathrm{~Pb}_{4} \mathrm{I}_{13}$

To better understand the two types of electrical conduction mechanisms, i.e., ohmic conduction in the LRS and Schottky emission in the HRS, the $I-V$ curves of each resistance state were replotted with linear fitting lines. From Fig. 5b, it is clear that the linear fitting conforms to the ohmic conduction in the LRS, as proven by the proportional relation of the current density to the voltage $(I \propto$ $V)^{53}$. This finding indicates that ohmic conduction governed the LRS after the abrupt formation of the conducting filament by passing through the halide perovskite switching layer.

To further clarify whether Schottky emission is dominant in the HRS region during the SET operation, the nonlinear $I-V$ curve of the HRS was replotted as $\ln I$ vs. the square root of the applied voltage $\left(\ln I \propto V^{1 / 2}\right)$, as illustrated in Fig. $5 \mathrm{c}^{52,55,56}$. The fitting result shows a linear relationship of $\ln I \propto V^{1 / 2}$, which can be taken as evidence that Schottky emission is dominant in the HRS region, according to the following equation: ${ }^{23}$

$$
\ln I \propto \sqrt{\frac{q^{3}}{4 \pi \varepsilon d} k T} \times \sqrt{V},
$$

where $I$ is the current, $q$ is the electric charge, $\varepsilon$ is the dielectric constant, $d$ is the dielectric film thickness, and $V$ is the applied voltage. The linearity of the replotted graph indicates that the metal cations are dissolved from the Ag top electrode by thermionic Schottky emission. In other words, in the HRS, Schottky contact is formed between the Ag top electrode and the halide perovskite layer, and the ejected carriers from the top electrode can easily pass through the potential barrier. Furthermore, the results suggest that the limited current flow from the top electrode to the switching layer controls the HRS current level.

It is known that the current in the HRS is related to the Schottky barrier height; thus, we compared the linear replotted $I-V$ curves for the HRS of the $3 \mathrm{D} \mathrm{CsPbI}_{3}$ and
quasi-2D (PEA) ${ }_{2} \mathrm{Cs}_{3} \mathrm{~Pb}_{4} \mathrm{I}_{13}$ memory devices. As shown in Fig. 6a, the quasi-2D (PEA) ${ }_{2} \mathrm{Cs}_{3} \mathrm{~Pb}_{4} \mathrm{I}_{13}$ memory device displayed a lower current in the HRS, where the current density could be estimated according to the Richardson-Schottky law:

$$
J=A \times T^{2} \times \exp \left(\frac{q \sqrt{\frac{q E}{4 \pi \varepsilon}}}{k T}-\frac{q \Phi_{\mathrm{B}}}{k T}\right)
$$

where $A$ is the Richardson constant, $E$ is the electric field, and $\Phi_{\mathrm{B}}$ is the Schottky barrier height ${ }^{57,58}$.

As expressed in Eq. (3), the Schottky barrier height, $\Phi_{\mathrm{B}}$, corresponds to the current density in the HRS. The increased barrier height of quasi-2D (PEA) $)_{2} \mathrm{Cs}_{3} \mathrm{~Pb}_{4} \mathrm{I}_{13}$ limits the carrier flow from the $\mathrm{Ag}$ top electrode to the perovskite switching layer. Figure $6 \mathrm{~b}$ shows a schematic representation of the Schottky barrier heights of these two perovskite materials, suggesting that the band bending induced by modifying the bandgap of the switching material controls the barrier height. Therefore, we can increase the HRS current to improve the ON/OFF ratio of the memory devices.

In the ECM mechanism, the formation and rupture of the metal cation filament are caused by electrochemical reactions as well as thermal effects; therefore, the temperature dependence of the memory devices should be investigated. To confirm the impact of temperature on the electrical characteristics of the device, $I-V$ measurements were conducted over the temperature range of 293 $-393 \mathrm{~K}$. Figure 7 a shows that the HRS current increased with increasing temperature. The increasing tendency of the current can be attributed to the easy migration of the ejected metal cations into the switching layer after the dissolution of the metal electrode ${ }^{23,59}$.

Figure $7 \mathrm{~b}-\mathrm{d}$ display the decreasing and increasing trends for the forming, SET, and RESET voltages under a DC 
(a)

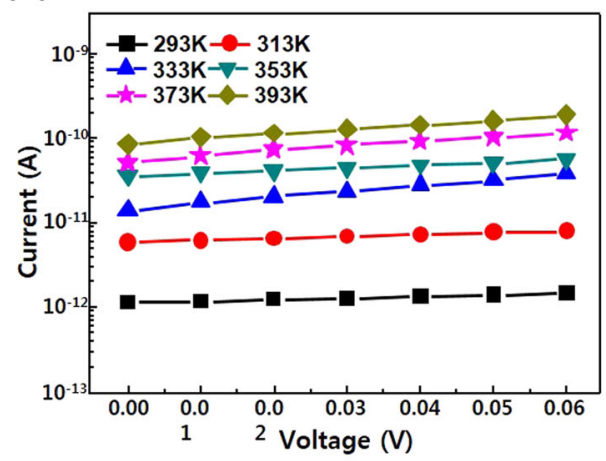

(c)

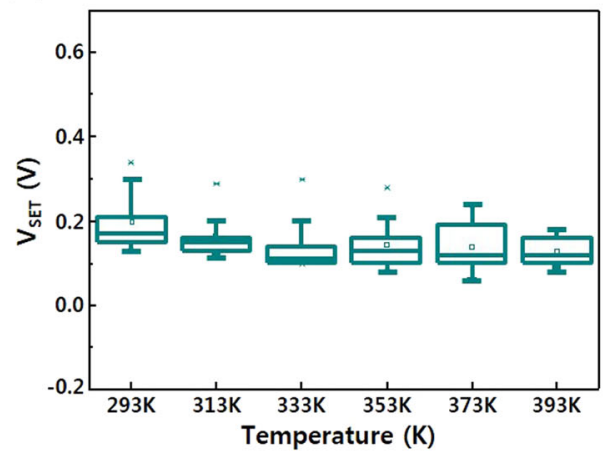

(b)

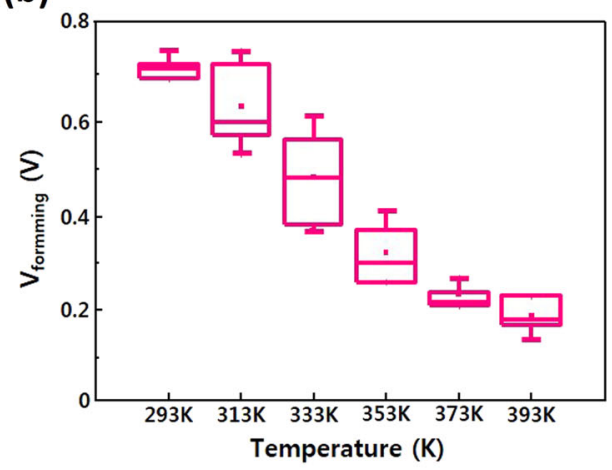

(d)

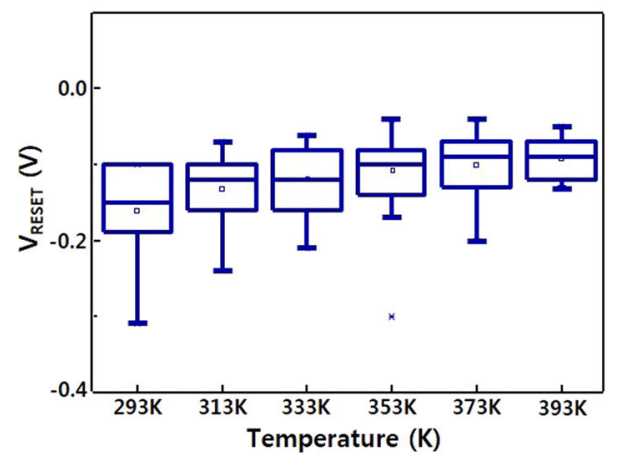

Fig. 7 Temperature dependence of the HRS before the SET process and tendency of the forming, SET, and RESET voltages under the DC voltage sweep with increasing temperature. a Temperature dependence of the HRS before the SET process. $\mathbf{b}, \mathbf{c}$, $\mathbf{d}$ Tendency of the forming (b), $\mathrm{SET}(\mathbf{c})$, and RESET (d) voltages under the DC voltage sweep with increasing temperature

voltage sweep when the temperature was elevated. In the forming and SET processes, the operating voltage is related to the rate of migration of the metal cations and the supersaturation of the metal. As the temperature increases, Ag metal cations easily move through a switching layer and then quickly reach supersaturation at the counter-electrode, even at a low voltage, thereby reducing the forming and SET voltages ${ }^{59,60}$. In the RESET processes, the rupture of the conducting filament at the counter-electrode occurs due to Joule heating-assisted dissolution ${ }^{59-61}$. The narrow conducting filaments, which are thermally unstable, are easily broken at high temperature. For this reason, the rupture of the $\mathrm{Ag}$ filament can easily take place at the counter-electrode as the temperature increases, even under a low-intensity electric field.

One of the issues for halide perovskite-based ReRAM devices is stability. It has been reported that the $\mathrm{CsPbI}_{3} 3 \mathrm{D}$ halide perovskite is susceptible to humidity, resulting in rapid degradation when related devices are exposed to ambient conditions. Recently, to enhance the moisture resistance, some techniques have been introduced to maintain the stability, such as encapsulation or applying passivating polymer films to the devices. In our work, we found that the $(\mathrm{PEA})_{2} \mathrm{Cs}_{3} \mathrm{~Pb}_{4} \mathrm{I}_{13}$ quasi-2D halide perovskite was more robust at room temperature under ambient conditions than the $\mathrm{CsPbI}_{3} 3 \mathrm{D}$ halide perovskites.

To confirm the superior stability of (PEA) ${ }_{2} \mathrm{Cs}_{3} \mathrm{~Pb}_{4} \mathrm{I}_{13}$, the memory devices were kept under ambient atmosphere and the $I-V$ characteristics were monitored. As illustrated in Fig. $8 \mathrm{a}$, the 3D perovskite memory device degraded after 5 days. However, from the $I-V$ measurements for the quasi-2D perovskite memory devices in Fig. 8b, it is clear that the stability was enhanced without appreciable decay after storage in air for 2 weeks. The stable resistive switching behavior of this $(\mathrm{PEA})_{2} \mathrm{Cs}_{3} \mathrm{~Pb}_{4} \mathrm{I}_{13}$ memory device is influenced by multiple interaction forces in the quasi-2D structure, such as strong ionic bonds in the perovskite (inorganic) layer, weak van der Waals forces between the PEA layers (mono-ammonium cation layers), and connections between the organic and inorganic layers (the coordination bonds between the ammonium group and $\mathrm{Pb}$, and the hydrogen bond between the ammonium group and halogen $)^{62,63}$. Furthermore, the hydrophobic PEA cation brings about steric hindrance, which affects the surface $\mathrm{Pb}-\mathrm{I}$ to prevent the adsorption of water ${ }^{64}$. In addition, the stacks of hydrophobic cation layers protect the inner perovskites from water molecules, thus minimizing the water intake by the memory devices. 
(a)

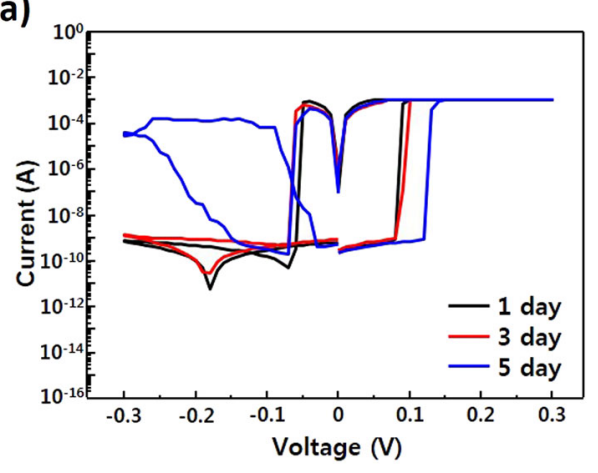

(b)

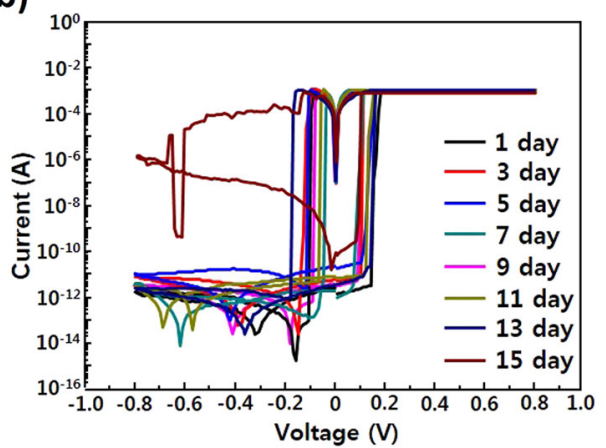

Fig. 8 Stability tests from the I-V measurements. Stability tests from the $\mathrm{I}-\mathrm{V}$ measurements of the $\mathrm{Ag} / \mathrm{CsPbl}_{3} / \mathrm{Pt}$ (a) and $\mathrm{Ag}$ / $(\mathrm{PEA})_{2} \mathrm{Cs}_{3} \mathrm{~Pb}_{4} \mathrm{I}_{13} / \mathrm{Pt}(\mathbf{b})$ devices

Thus, we confirmed that the PEA cations prevent the destruction of the quasi-2D structure and provide moisture resistance, which counters the degradation of the switching performance of the $(\mathrm{PEA})_{2} \mathrm{Cs}_{3} \mathrm{~Pb}_{4} \mathrm{I}_{13}$ memory device.

\section{Conclusion}

In summary, a large ionic radius cation (PEA) was introduced into $\mathrm{CsPb}_{3}$ to form a quasi-2D halide perovskite, $(\mathrm{PEA})_{2} \mathrm{Cs}_{3} \mathrm{~Pb}_{4} \mathrm{I}_{13}$, to achieve a high $\mathrm{ON} / \mathrm{OFF}$ ratio in ReRAM devices. A uniform surface morphology was achieved by incorporating the PEA cation and $\mathrm{PEA})_{2} \mathrm{Cs}_{3} \mathrm{~Pb}_{4} \mathrm{I}_{13}$ effectively improved the resistive switching of the device. The ReRAM device with the Ag/ $(\mathrm{PEA})_{2} \mathrm{Cs}_{3} \mathrm{~Pb}_{4} \mathrm{I}_{13} / \mathrm{Pt}$ structure showed a high ON/OFF ratio of $10^{9}$, which is three orders higher than that of the $\mathrm{CsPbI}_{3}-$ based memory device. Owing to the wide bandgap of $(\mathrm{PEA})_{2} \mathrm{Cs}_{3} \mathrm{~Pb}_{4} \mathrm{I}_{13}$, a high Schottky barrier was formed and the activation energy increased, thereby leading to a reduction in the HRS current. A stability test verified the superior resistance of the device under ambient atmosphere at room temperature, which is another favorable property of quasi-2D perovskites. Although the $\mathrm{CsPb}_{3}$ memory device was degraded after 5 days, the $(\mathrm{PEA})_{2} \mathrm{Cs}_{3} \mathrm{~Pb}_{4} \mathrm{I}_{13}$ devices were stable for 2 weeks, which is meaningful in terms of the practical application of halide perovskite memory devices.
Table 1 Comparison of various halide perovskite-based ReRAM devices

\begin{tabular}{|c|c|c|c|}
\hline Device structure & $\begin{array}{l}\text { SET voltage } \\
{\left[V_{\text {set }}\right]}\end{array}$ & ON/OFF ratio & Ref. \\
\hline $\mathrm{Au} / \mathrm{MAPb}_{3-x} \mathrm{Cl}_{x} / \mathrm{FTO}$ & 0.8 & 10 & 65 \\
\hline $\mathrm{Au} /\left.\mathrm{MAPbCl}\right|_{x-x} / \mathrm{TIO}_{2} / \mathrm{Ti}$ & 1 & 20 & 66 \\
\hline W/Oleic acid-MAPbl$/ 3 / F T O$ & 3.1 & $10^{2}$ & 67 \\
\hline $\mathrm{Au} / \mathrm{MAPbl}_{3} / \mathrm{ITO}$ & 0.7 & $10^{2}$ & 20 \\
\hline $\mathrm{Al} / \mathrm{CsPbBr}_{3} / \mathrm{PEDOT}: \mathrm{PSS} / \mathrm{ITO}$ & $|-0.6|$ & $10^{2}$ & 68 \\
\hline $\mathrm{Au} / \mathrm{ZnO} / \mathrm{MAPb}_{3} / \mathrm{ITO}$ & 0.9 & $10^{2}$ & 69 \\
\hline $\mathrm{Au} / \mathrm{MA}_{3} \mathrm{Bi}_{2} \mathrm{I}_{\mathrm{g}} / \mathrm{ITO}$ & 1.6 & $10^{2}$ & 70 \\
\hline $\begin{array}{l}\mathrm{Ag} / \mathrm{PMMA} / \mathrm{MAPb}_{3} / \mathrm{PMMA} \\
\text { ITO }\end{array}$ & 1.2 & $10^{3}$ & 71 \\
\hline $\begin{array}{l}\text { Ag/PMMA/MAPbBr } 3: P M M A / \\
\text { PMMA/ITO }\end{array}$ & 1 & $10^{3}$ & 72 \\
\hline $\mathrm{Au} / \mathrm{Cs}_{3} \mathrm{Bi}_{2} \mathrm{l}_{9} / \mathrm{ITO}$ & 0.3 & $10^{3}$ & 73 \\
\hline $\mathrm{Au} / \mathrm{MAPbl}_{3} / \mathrm{Pt}$ & 1 & $10^{4}$ & 74 \\
\hline $\mathrm{Ag} / \mathrm{PMMA} / \mathrm{CsSnl}_{3} / \mathrm{Pt}$ & 0.13 & $10^{5}$ & 59 \\
\hline $\mathrm{Ni} / \mathrm{ZnO} / \mathrm{CsPbBr}_{3} / \mathrm{FTO}$ & $|-0.95|$ & $10^{5}$ & 75 \\
\hline $\mathrm{Ag} / \mathrm{MAPbl}_{3} / \mathrm{Pt}$ & 0.2 & $10^{6}$ & 18 \\
\hline $\mathrm{Ag} / \mathrm{PMMA} / \mathrm{CsPb}_{3} / \mathrm{Pt}$ & 0.18 & $10^{6}$ & 23 \\
\hline $\begin{array}{l}\mathrm{Ag} / \mathrm{PMMA} / \mathrm{Rb}_{0.52 \mathrm{MA0} .48} \mathrm{~Pb}_{3} / \\
\mathrm{Pt}\end{array}$ & 0.25 & $10^{6}$ & 76 \\
\hline $\mathrm{Ag} / \mathrm{MAPbl}_{3} / \mathrm{Pt}$ & 0.13 & $10^{6}$ & 22 \\
\hline $\mathrm{Ag} / \mathrm{CsPbl}_{3} / \mathrm{Pt}$ & 0.1 & $10^{6}$ & This work \\
\hline $\mathrm{Au} / \mathrm{Rb}_{3} \mathrm{Bi}_{2} \mathrm{l}_{9}\left(\mathrm{Cs}_{3} \mathrm{Bi}_{2} \mathrm{l}_{9}\right) / \mathrm{Pt}$ & $0.09(0.1)$ & $10^{7}$ & 77 \\
\hline $\mathrm{Au} / \mathrm{MAPbl}_{3} / \mathrm{Au}$ & 0.32 & $10^{7}$ & 78 \\
\hline $\mathrm{Ag} / \mathrm{PEA}_{2} \mathrm{Cs}_{3} \mathrm{~Pb}_{4} \mathrm{I}_{13} / \mathrm{Pt}$ & 0.18 & $10^{9}$ & This work \\
\hline
\end{tabular}

\section{Experimental section Materials}

Lead(II) iodide (99.9985\%) and hydroiodic acid (57\% in aqueous solution, stabilized with $1.5 \%$ hydrophosphorous acid) were provided by Alfa Aesar (Thermo Fisher Scientific, USA). Phenylethylamine (>99\%), cesium iodide (99.99\%), poly(methyl methacrylate), chlorobenzene (anhydrous, 99.8\%), and N,N-dimethylformamide (anhydrous, 99.8\%) were purchased from Sigma-Aldrich (USA). All the materials were used without any further purification.

\section{Synthesis of PEAI}

Phenylethylamine $(80 \mathrm{mmol})$ was dissolved in $10 \mathrm{~mL}$ of ethanol and placed in an ice bath. HI $(20 \mathrm{~mL})$ was then slowly added to the flask and was kept for 20 min under vigorous stirring. The white powder (PEAI) was collected using a rotary evaporator and washed thrice with diethyl ether. Finally, the product was dried under vacuum at $50{ }^{\circ} \mathrm{C}$ for 1 day before use (Table 1 ).

\section{Fabrication of the memory devices}

Different dimensional perovskite $\left(\mathrm{PEA}_{2} \mathrm{Cs}_{n-1} \mathrm{PbnI}_{3 n+1}\right)$ precursors were prepared by mixing stoichiometric quantities of PEAI, CsI, and $\mathrm{PbI}_{2}$ in N,N-dimethylformamide (DMF, anhydrous, 99.8\%) at a concentration of 
$40 \mathrm{wt} \%$, followed by heating for $12 \mathrm{~h}$. A small amount of HI was added to the solution to increase the solubility of PEAI. A uniform film was obtained by spin-coating the precursor on $\mathrm{Pt} / \mathrm{Ti} / \mathrm{SiO}_{2} / \mathrm{Si}$ substrates at a speed of $4000 \mathrm{r}$. p.m. and heating at $150^{\circ} \mathrm{C}$ for $5 \mathrm{~min}$. The PMMA (polymethylmethacrylate) solution $\left(5 \mathrm{mg} \mathrm{mL}^{-1}\right)$ was spincoated to protect the perovskite film from moisture. After deposition of PMMA, the films were further heated at $100^{\circ} \mathrm{C}$ for $5 \mathrm{~min}$. To complete the devices, Ag electrodes $(50 \mu \mathrm{m} \times 50 \mu \mathrm{m})$ were deposited by e-beam evaporation under $1 \times 10^{-6}$ Torr at room temperature through a shadow mask.

\section{Characterization}

The surfaces and cross-sections of the perovskite films were imaged using a field-emission SEM (ZEISS MERLIN COMPACT). The morphology of the perovskite films was analyzed using AFM (Park System XE100). The XRD patterns were recorded using an X-ray diffractometer (Bruker Miller Co., D8-Advance) with $\mathrm{Cu}-\mathrm{K} \alpha$ radiation. The electrical properties of the memory units were characterized by using an Agilent 4156C semiconductor analyzer in the direct current-voltage sweeping mode and alternating voltage pulse mode in a vacuum chamber $\left(6 \times 10^{-2}\right.$ Torr $)$.

\section{Acknowledgements}

This work was financially supported by the Future Material Discovery (2016M3D1A1027666) Program, the Basic Research Laboratory (2018R1A4A1022647), and the National Research Foundation of Korea (NRF) grant funded by the Korean government MSIT (2019M3E6A1103818).

\section{Author details}

${ }^{1}$ Department of Materials Science and Engineering, Seoul National University, Seoul 08826, Republic of Korea. ${ }^{2}$ Institute of Research and Development, Duy Tan University, Da Nang 550000, Vietnam. ${ }^{3}$ Department of Materials Science and Engineering, Korea University, Seoul 02841, Republic of Korea

\section{Conflict of interest}

The authors declare that they have no conflict of interest.

\section{Publisher's note}

Springer Nature remains neutral with regard to jurisdictional claims in published maps and institutional affiliations.

Supplementary information is available for this paper at https://doi.org/ 10.1038/s41427-020-0202-2.

Received: 12 November 2019 Revised: 23 December 2019 Accepted: 7 January 2020.

Published online: 28 February 2020

\section{References}

1. Green, M. A., Ho-Baillie, A. \& Snaith, H. J. The emergence of perovskite solar cells. Nat. Photonics 8, 506-514 (2014).

2. Kim, H., Veerappan, G. \& Park, J. H. Conducting polymer coated non-woven graphite fiber film for dye-sensitized solar cells: superior Pt- and FTO-free counter electrodes. Electrochim. Acta 137, 164-168 (2014).

3. Kim, H., Veerappan, G., Wang, D. H. \& Park, J. H. Large area platinum and fluorine-doped tin oxide-free dye sensitized solar cells with silver-nanoplate embedded poly(3,4-ethylenedioxythiophene) counter electrode. Electrochim. Acta 187, 218-223 (2016).

4. Shibayama, N. et al. All-inorganic inverse perovskite solar cells using zinc oxide nanocolloids on spin coated perovskite layer. Nano Converg. 4, 18 (2017).

5. Patel, M., Park, S. \& Kim, J. Rapid thermal treatment of reactive sputtering grown nanocrystalline $\mathrm{CO}_{3} \mathrm{O}_{4}$ for enhanced all-oxide photovoltaics. Phys. Stat. Solid. A 1800216, 1-10 (2018).

6. Kim, H. \& Kim, J. Data in brief statistical analyses on Si microwire solar cells. Data Br. 12, 42-45 (2017).

7. Kim, H. et al. Solar energy materials \& solar cells electrical and optical properties of Si microwire solar cells. Sol. Energy Mater. Sol. Cells 164, 7-12 (2017).

8. Kumar, M. et al. Switchable two-terminal transparent optoelectronic devices based on 2D perovskite. Adv. Electron. Mater. 1800662, 1-7 (2019).

9. Dong, Y., Parobek, D. \& Son, D. H. Controlling quantum confinement and magnetic doping of cesium lead halide perovskite nanocrystals. J. Korean Ceram. Soc. 55, 515-526 (2018).

10. Jo, J. W., Yoo, Y., Jeong, T., Ahn, S. \& Ko, M. J. Low-temperature processable charge transporting materials for the flexible perovskite solar cells. Electron. Mater. Lett. 14, 657-668 (2018).

11. Sheikh, M. A. K. et al. Effects of chlorine contents on perovskite solar cell structure formed on CdS electron transport layer probed by Rutherford backscattering. Electron. Mater. Lett. 14, 700-711 (2018).

12. Wadi, M. A. A. et al. Evolution of Pb-free and partially Pb-substituted perovskite absorbers for efficient perovskite solar cells. Electron. Mater. Lett. 15, 525-546 (2019).

13. Jung, Y.-J., Cho, S.-Y., Jung, J.-W., Kim, S.-Y. \& Lee, J.-H. Influence of indium-tinoxide and emitting-layer thicknesses on light outcoupling of perovskite lightemitting diodes. Nano Converg. 6, 26 (2019).

14. Park, N.-G. Methodologies for high efficiency perovskite solar cells. Nano Converg. 3, 15 (2016).

15. Ren, X. \& Jung, H. S. Recent progress in flexible perovskite solar cell development. J. Korean Ceram. Soc. 55, 325-336 (2018).

16. Gil, B. et al. Recent progress in inorganic hole transport materials for efficient and stable perovskite solar cells. Electron. Mater. Lett. 15, 505-524 (2019).

17. Choi, J., Han, J. S., Hong, K., Kim, S. Y. \& Jang, H. W. Organic-inorganic hybrid halide perovskites for memories, transistors, and artificial synapses. Adv. Mater. 30, 1704002 (2018).

18. Choi, J. et al. Enhanced endurance organolead halide perovskite resistive switching memories operable under an extremely low bending radius. ACS Appl. Mater. Interfaces 9, 30764-30771 (2017).

19. Kim, S. G., Han, J. S., Kim, H., Kim, S. Y. \& Jang, H. W. Recent advances in memristive materials for artificial synapses. Adv. Mater. Technol. 3, 1800457 (2018).

20. Gu, C. \& Lee, J.-S. Flexible hybrid organic-inorganic perovskite memory. ACS Nano 10, 5413-5418 (2016).

21. Kim, H., Han, J. S., Choi, J., Kim, S. Y. \& Jang, H. W. Halide perovskites for applications beyond photovoltaics. Small Methods 2, 1700310 (2018).

22. Choi, J. et al. Organolead halide perovskites for low operating voltage multilevel resistive switching. Adv. Mater. 28, 6562-6567 (2016).

23. Han, J. S. et al. Air-stable cesium lead iodide perovskite for ultra-low operating voltage resistive switching. Adv. Funct. Mater. 28, 1705783 (2018).

24. $\mathrm{Hu}, \mathrm{W}$. et al. Opportunity of spinel ferrite materials in nonvolatile memory device applications based on their resistive switching performances. J. Am. Chem. Soc. 134, 14658-14661 (2012).

25. Michelakaki, I., Bousoulas, P., Stathopoulos, S., Boukos, N. \& Tsoukalas, D. Coexistence of bipolar and threshold resistive switching in $\mathrm{TiO}_{2}$ based structure with embedded hafnium nanoparticles. J. Phys. D. Appl. Phys. 50, 045103 (2017).

26. Huang, $\mathrm{Y}$. et al. Amorphous $\mathrm{ZnO}$ based resistive random access memory. RSC Adv. 6, 17867-17872 (2016).

27. Wang, $\mathrm{Y}$. et al. Efficient $\mathrm{a}-\mathrm{CsPb}_{3}$ photovoltaics with surface terminated organic cations. Joule 2, 2065-2075 (2018).

28. Jia, G. et al. Super air stable quasi-2D organic-inorganic hybrid perovskites for visible light-emitting diodes. Opt. Express 26, A66 (2018).

29. Han, Y., Park, S., Kim, C., Lee, M. \& Hwang, I. Phase control of quasi-2D perovskites and improved light-emitting performance by excess organic cations and nanoparticle intercalation. Nanoscale 11, 3546-3556 (2019).

30. Li, F. et al. Tailored dimensionality to regulate the phase stability of inorganic cesium lead iodide perovskites. Nanoscale 10, 6318-6322 (2018). 
31. Yan, J., Qiu, W., Wu, G., Heremans, P. \& Chen, H. Recent progress in 2D/quasi2D layered metal halide perovskites for solar cells. J. Mater. Chem. A 6 11063-11077 (2018).

32. Fan, J. et al. Thermodynamically self-healing 1D-3D hHybrid perovskite solar cells. Adv. Energy Mater. 8, 1703421 (2018).

33. $\mathrm{Ng}, \mathrm{Y}$. F. et al. Highly efficient Cs-based perovskite light-emitting diodes enabled by energy funnelling. Chem. Commun. 53, 12004-12007 (2017).

34. Gebhardt, J., Kim, Y. \& Rappe, A. M. Influence of the dimensionality and organic cation on crystal and electronic structure of organometallic halide perovskites. J. Phys. Chem. C. 121, 6569-6574 (2017).

35. Ma, S. et al. Two-dimensional organic-inorganic hybrid perovskite: from material properties to device applications. Sci. China Mater. 61, 1257-1277 (2018).

36. Quan, L. N. et al. Ligand-stabilized reduced-dimensionality perovskites. J. Am. Chem. Soc. 138, 2649-2655 (2016).

37. Liao, Y. et al. Highly oriented low-dimensional tin halide perovskites with enhanced stability and photovoltaic performance. J. Am. Chem. Soc. 139, 6693-6699 (2017)

38. Wang, Z. et al. Efficient ambient-air-stable solar cells with 2D-3D heterostructured butylammonium-caesium-formamidinium lead halide perovskites. Nat. Energy 2, 17135 (2017).

39. Hong, K., Le, Q., Van, Kim, S. Y. \& Jang, H. W. Low-dimensional halide perovskites: review and issues. J. Mater. Chem. C 6, 2189-2209 (2018).

40. Seo, J.-Y. et al. Wafer-scale reliable switching memory based on 2-dimensional layered organic-inorganic halide perovskite. Nanoscale 9, 15278-15285 (2017).

41. Kim, H., Huynh, K. A., Kim, S. Y., Le, Q. Van \& Jang, H. W. 2D and quasi-2D halide perovskites: applications and progress. Phys. Stat. Solid. Rapid Res. Lett. 3, 1900435 (2019)

42. Misra, R. K., Cohen, B.-E., lagher, L. \& Etgar, L. Low-dimensional organic-inorganic halide perovskite: structure, properties, and applications. ChemSusChem 10, 3712-3721 (2017)

43. Ban, M. et al. Solution-processed perovskite light emitting diodes with efficiency exceeding 15\% through additive-controlled nanostructure tailoring. Nat. Commun. 9, 3892 (2018).

44. Kumawat, N. K., Gupta, D. \& Kabra, D. Recent advances in metal halide-based perovskite light-emitting diodes. Energy Technol. 5, 1734-1749 (2017).

45. Eperon, G. E. et al. Inorganic caesium lead iodide perovskite solar cells. J. Mater. Chem. A 3, 19688-19695 (2015).

46. Jiang, $Y$. et al. Reduced-dimensional a-CsPbX 3 perovskites for efficient and stable photovoltaics. Joule 2, 1356-1368 (2018).

47. Huang, H.W. et al. Stability scheme of $\mathrm{ZnO}$-thin film resistive switching memory: influence of defects by controllable oxygen pressure ratio. Nanoscale Res. Lett. 8, 483 (2013).

48. Kim, H., Han, J. S., Kim, S. G., Kim, S. Y. \& Jang, H. W. Halide perovskites for resistive random-access memories. J. Mater. Chem. C 7, 5226-5234 (2019).

49. Zhu, W., Chen, T. P., Liu, Y. \& Fung, S. Conduction mechanisms at low- and high-resistance states in aluminum/anodic aluminum oxide/aluminum thin film structure. J. Appl. Phys. 112, 063706 (2012).

50. Park, T. H. et al. Thickness-dependent electroforming behavior of ultra-thin $\mathrm{Ta}_{2} \mathrm{O}_{5}$ resistance switching layer. Phys. Stat. Solid. Rapid Res. Lett. 9, 362-365 (2015).

51. Waser, R., Dittmann, R., Staikov, G., Szot, K. \& Redox-Based Resistive Switching Memories, - Nanoionic mechanisms, prospects, and challenges. Adv. Mater. 21 2632-2663 (2009).

52. Rana, A. M. et al. Endurance and cycle-to-cycle uniformity improvement in trilayered $\mathrm{CeO}_{2} / \mathrm{Ti} / \mathrm{CeO}_{2}$ resistive switching devices by changing top electrode material. Sci. Rep. 7, 39539 (2017).

53. Lim, E. \& Ismail, R. Conduction mechanism of valence change resistive switching memory: a survey. Electronics 4, 586-613 (2015).

54. Lin, L.-M. et al. A novel nanoscale-crossbar resistive switching memory using a copper chemical displacement technique. Phys. Stat. Solid. 214, 1600595 (2017).

55. Loy, D. J. J., Dananjaya, P. A., Hong, X. L., Shum, D. P. \& Lew, W. S. Conduction mechanisms on high retention annealed MgO-based resistive switching memory devices. Sci. Rep. 8, 14774 (2018).
56. Wu, C.-H. et al. Effect of charge quantity on conduction mechanism of highand low-resistance states during forming process in a one-transistor-oneresistor resistance random access memory. Appl. Phys. Express 10, 054101 (2017).

57. Park, J. et al. Multibit operation of $\mathrm{TiO}_{\mathrm{x}}$-based ReRAM by Schottky barrier height engineering. IEEE Electron. Device Lett. 32, 476-478 (2011)

58. Chen, S. C., Lou, J. C., Chien, C. H., Liu, P. T. \& Chang, T. C. An interfacial investigation of high-dielectric constant material hafnium oxide on Si substrate. Thin Solid Films 488, 167-172 (2005).

59. Han, J. S. et al. Lead-free all-inorganic cesium tin iodide perovskite for filamentary and interface-type resistive switching toward environment-friendly and temperature-tolerant nonvolatile memories. ACS Appl. Mater. Interfaces 11, 8155-8163 (2019)

60. Tsuruoka, T., Terabe, K., Hasegawa, T. \& Aono, M. Temperature effects on the switching kinetics of a $\mathrm{Cu}-\mathrm{Ta}_{2} \mathrm{O}_{5}$-based atomic switch. Nanotechnology 22, 254013 (2011).

61. Tsuruoka, T., Terabe, K., Hasegawa, T. \& Aono, M. Forming and switching mechanisms of a cation-migration-based oxide resistive memory. Nanotechnology 21, 425205 (2010).

62. Xu, F., Zhang, T., Li, G. \& Zhao, Y. Mixed cation hybrid lead halide perovskites with enhanced performance and stability. J. Mater. Chem. A 5, 11450-11461 (2017).

63. Zhu, $X$. et al. Vapor-fumigation for record efficiency two-dimensional perovskite solar cells with superior stability. Energy Environ. Sci. 11, 3349-3357 (2018).

64. Yang, S. et al. Functionalization of perovskite thin films with moisture-tolerant molecules. Nat. Energy 1, 15016 (2016).

65. Yoo, E. J. et al. Resistive switching behavior in organic-inorganic hybrid $\mathrm{CH}_{3} \mathrm{NH}_{3} \mathrm{Pbl}_{3-x} \mathrm{Cl}_{x}$ perovskite for resistive random access memory devices. Adv Mater. 27, 6170-6175 (2015).

66. Yan, K. et al. First fiber-shaped non-volatile memory device based on hybrid organic-inorganic perovskite. Adv. Electron. Mater. 2, 1600160 (2016).

67. Cai, H., Ma, G., He, Y., Liu, C. \& Wang, H. A remarkable performance of $\mathrm{CH}_{3} \mathrm{NH}_{3} \mathrm{~Pb}_{3}$ perovskite memory based on passivated method. Org. Electron. 58, 301-305 (2018).

68. Liu, D. et al. Flexible all-inorganic perovskite $\mathrm{CsPbBr}_{3}$ nonvolatile memory device. ACS Appl. Mater. Interfaces 9, 6171-6176 (2017).

69. Hwang, B. \& Lee, J-S. Hybrid organic-inorganic perovskite memory with longterm stability in air. Sci. Rep. 7, 673 (2017).

70. Hwang, B. \& Lee, J.-S. Lead-free, air-stable hybrid organic-inorganic perovskite resistive switching memory with ultrafast switching and multilevel data storage. Nanoscale 10, 8578-8584 (2018).

71. Liu, Y. et al. Resistive switching memory based on organic/inorganic hybrid perovskite materials. Vacuum 130, 109-112 (2016).

72. Yang, K. Li, F., Veeramalai, C. P. \& Guo, T. A facile synthesis of $\mathrm{CH}_{3} \mathrm{NH}_{3} \mathrm{PbBr}_{3}$ perovskite quantum dots and their application in flexible nonvolatile memory. Appl. Phys. Lett. 110, 083102 (2017).

73. $\mathrm{Hu}$, Y. et al. Ultrathin $\mathrm{CS}_{3} \mathrm{Bi}_{2} \mathrm{l}_{9}$ nanosheets as an electronic memory material for flexible memristors. Adv. Mater. Interfaces 4, 1700131 (2017).

74. Hwang, B. \& Lee, J.-S. A strategy to design high-density nanoscale devices utilizing vapor deposition of metal halide perovskite materials. Adv. Mater. 29 1701048 (2017).

75. Wu, Y. et al. Capping $\mathrm{CsPbBr}_{3}$ with $\mathrm{ZnO}$ to improve performance and stability of perovskite memristors. Nano Res 10, 1584-1594 (2017).

76. Lee, $\mathrm{S}$. et al. Conducting bridge resistive switching behaviors in cubic $\mathrm{MAPb}_{3}$ orthorhombic $\mathrm{RbPb}_{3}$, and their mixtures. Adv. Electron. Mater. 5, 1800586 (2019).

77. Cuhadar, $\mathrm{C}$. et al. All-inorganic bismuth halide perovskite-like materials $\mathrm{A}_{3} \mathrm{Bi}_{2} \mathrm{l}_{9}$ and $\mathrm{A}_{3} \mathrm{Bi}_{1.8} \mathrm{Na}_{0.2}$ l.6.6 $_{\text {( }} \mathrm{A}=\mathrm{Rb}$ and $\mathrm{Cs}$ ) for low-voltage switching resistive memory. ACS Appl. Mater. Interfaces 10, $29741-29749$ (2018).

78. Zhu, X., Lee, J. \& Lu, W. D. lodine vacancy redistribution in organic-inorganic halide perovskite films and resistive switching effects. Adv. Mater. 29, 1700527 (2017). 